PAPER

\title{
The debate about physician assistance in dying: 40 years of unrivalled progress in medical ethics?
}

\author{
Søren Holm ${ }^{1,2,3}$
}

${ }^{1}$ Centre for Social Ethics and Policy, School of Law, University of Manchester, Manchester, UK

${ }^{2}$ Faculty of Medicine, Centre for Medical Ethics, HELSAM, University of Oslo, Oslo, Norway

${ }^{3}$ Centre for Ethics in Practice, Aalborg University, Aalborg, Denmark

\section{Correspondence to}

Professor Søren Holm, Centre for Social Ethics and Policy, School of Law, University of Manchester, Manchester M13 9PL, UK;

Soren.holm@manchester.ac.uk

Received 1 September 2014 Revised 28 October 2014 Accepted 29 October 2014
CrossMark

To cite: Holm S. J Med Ethics 2015;41:40-43.

\section{ABSTRACT}

Some issues in medical ethics have been present throughout the history of medicine, and thus provide us with an opportunity to ascertain: (1) whether there is progress in medical ethics; and (2) what it means to do good medical ethics. One such perennial issue is physician assistance in dying (PAD). This paper provides an account of the PAD debate in this journal over the last 40 years. It concludes that there is some (but limited) progress in the debate. The distinctions, analogies and hypothetical examples have proliferated, as have empirical studies, but very little has changed in terms of the basic arguments. The paper further argues that many of the contributions to the debate fail to engage fully with the concerns people have about the legal introduction of PAD in the healthcare system, perhaps because many of the contributions sit on the borderline between academic analysis and social activism.

\section{INTRODUCTION}

The popularity of some issues in medical ethics waxes and wanes as a consequence of scientific developments, but other issues are perennial and can be traced far back in the history of medicine. One of these is physician assistance in dying (PAD), either in the form of euthanasia or physicianassisted suicide. Analysing the academic debate about PAD as it develops over time will therefore allow us to gain an insight into (1) to what degree there is progress in medical ethics; and (2) what it means to do good medical ethics. This paper will use articles published in the Journal of Medical Ethics (JME) as its exemplars, but the analysis is general and could equally have used articles from any of the other 'old' medical ethics journals. Between 1975 and the middle of August 2014 the $J M E$ has published 344 items with 'end of life' in the title or abstract, 241 items with 'euthanasia', 117 with 'assisted suicide' and 27 with 'terminal sedation' or one of its cognates (there is some overlap between these four groups), so there is a significant corpus of work to study. This paper is not based on a formal content analysis of all of these papers, but prior to writing the present paper all of the abstracts and a significant proportion of the full papers have been read and their meaning pondered.

\section{THE CONTOURS OF THE DEBATE}

The debate about PAD is multifaceted and has a different inflection in different jurisdictions, but at the core there are two central questions that are interconnected, but distinct: (1) is some type of PAD ethically acceptable or ethically mandatory in specific cases or classes of cases, and (2) should some type of PAD be legally allowed and, if so, under what conditions?

Papers on PAD appeared in the first volume of the journal and from early on there were both analytical and empirical papers. ${ }^{1}{ }^{2}$ Already in 1975 a paper outlined some of the distinctions that can be made in relation to euthanasia. ${ }^{1}$ We still today discuss what distinguishes different kinds of PAD and whether those distinctions are morally relevant. The 1975 paper distinguishes between active and passive euthanasia, and although that particular distinction is not so popular any more, we have new discussions about, for instance, distinctions between euthanasia and terminal sedation. ${ }^{3}$ In 1977 we find the first survey of the attitudes of healthcare professionals towards PAD. ${ }^{2}$

The main arguments in the debate can also be distinguished early on. On the liberal side of the debate we have arguments relating to suffering, autonomy and the right to a dignified death, and on the conservative side there are arguments relating to the proper role of medicine (or physicians), possible slippery slopes and the value/sanctity of life. Over time these arguments have been revised and refined, and each side has developed increasingly clever counterarguments, but there is little sign that either side has ever managed to convince their opponents to change opinion merely by the weight of rational argument. There is also very little evidence that it is the arguments of philosophers that have led to a change in societal attitudes. ${ }^{4}$ In the USA, at least the changes in attitudes to PAD seem to fit with a general long-term 'secular shift' where each new cohort has slightly more liberal attitudes than the preceding cohort to this and many other social issues. ${ }^{5}$

But can we nevertheless detect progress in the academic debate about PAD?

\section{PROGRESS IN EMPIRICAL ETHICS?}

The debate about PAD has generated a very significant amount of empirical research which can be roughly divided into four types of studies according to the research question - that is, studies investigating:

1. Attitudes and opinions of the public, patients or healthcare professionals in a particular country or institution in relation to PAD

2. Frequency of different types of PAD in a particular country or institution

3. Changes in the frequency of different types of PAD in a particular country or institution (potentially after changes in policy)

4. Description of particular types of PAD practice 
Studies of the first type are by far the most common and appear very early in the JME, but unfortunately they are the type that is least relevant to the normative question of the moral acceptability of PAD. Having evidence concerning the attitudes and opinions of various groups may be pragmatically important for the policy maker in deciding to what degree particular policy options may suffer resistance, but the evidence about attitudes tells us nothing about whether PAD is morally acceptable or should be legalised. Studies of types 2-4 are not as numerous, probably because they are more difficult to conduct, but can be far more relevant to the normative ethical analysis and to the discussion of PAD policy options.

Empirical evidence from the Netherlands has been very important in discussions about slippery slopes from voluntary to non-voluntary euthanasia, ${ }^{6}$ and an in-depth analysis of the Oregon experience with physician-assisted suicide has illuminated debates about the characteristics of patients seeking PAD. ${ }^{7}$

The main studies of the situation in the Netherlands have been published in the general medical literature, but the secondary discussion of how the numbers should be interpreted has been prominent in the JME. In this debate it has been evident that, whereas the numbers may to some extent be accepted as 'facts', their interpretation is very much influenced by the prior views on euthanasia held by the interpreter, as evidenced in the 1999 debate between Jochemsen/Keown and van Delden about the 'correct' interpretation of the data from the Netherlands. $^{8-10}$ This point has also been noted by Coggon. ${ }^{11}$

Empirical evidence rarely settles ethical questions conclusively, but both the Netherlands and the Oregon studies exemplify progress in empirical ethics because these studies have been explicitly designed to generate the kind of evidence that is relevant to a particular ethical debate-in this case, debates about slippery slopes and about whether or not 'the vulnerable' are likely to be pressured to seek PAD.

\section{PROGRESS IN PHILOSOPHICAL MEDICAL ETHICS?}

The naïve outsider might think that philosophical analysis of an ethical question proceeds in the following way. A question arises, the philosopher clarifies the question and marshals the extant arguments relevant to answering the question, s/he evaluates the extant arguments and develops new arguments if necessary to answer the question, and finally s/he provides a reasoned answer to the question.

The PAD debate, however, shows that this is an inaccurate picture of the actual modus operandi of academic medical ethics. One would be hard pressed to find an academic contribution to the debate that does not proceed in the reverse orderthat is, the philosopher knows the answer to the question, works hard to find the arguments that support that answer and discredit those arguments that do not, and then often reconstructs and presents the research process in the published paper as if it had been a dispassionate investigation of the question.

This is not a problem for the insiders who have written papers in this mode themselves and know that the genre requires methodological re-description. But it may be a problem for the outsiders who only infrequently read academic medical ethics and may not know that the apparent approach does not match the real approach.

This particular feature of the genre 'academic medical ethics paper' makes it difficult to establish whether and in what way there has been progress in philosophical medical ethics relating to PAD. This problem is compounded by the fact that the academic medical ethics paper is short, and that it would be unreasonable to require all of the reasoning from foundational moral theory to conclusion to be laid out in detail. There is no doubt that we now have more distinctions, more analogies and more hypothetical examples with which to illuminate our analysis of PAD issues, but a mere proliferation of distinctions may not necessarily be progress, although a proliferation of interesting questions might be.

There are probably many types of philosophical progress, but here I want to investigate only one which is potentially relevant to the PAD debate. In this debate we can claim a fairly minimal type of progress if later contributions to the debate take adequate account of previous contributions or at least of previous contributions on the same side of the debate. This is a modest account of progress that does not require what Rorty ${ }^{12}$ calls 'genius' to count as progress, but does fit the task he assigns to most of us as philosophical underlabourers mopping up after the genius:

Progress in this field, as in most others, is made by a few people in each generation glimpsing a possibility that had not previously been grasped. [...] The rest of us-the underlaborers to whom it is left to clean up and dispose of what these imaginative pioneers have seen to be rubbish-perform a useful social function. We do the dirty work. [p. 8]

But even on this fairly minimal account of progress it is possible seriously to doubt that progress has occurred. The same arguments are rehashed again and again without any apparent clearing away of old arguments or addition of really new arguments. This may perhaps be because no one has recently glimpsed an interesting philosophical possibility in relation to PAD that had not previously been grasped, but it may also be because the contributors to the debate each continue to frame the question in a way that is most conducive to their own position.

In 2012 we can, for instance, read the following fairly categorical statement in a commentary on continuous deep sedation: ${ }^{13}$

In assisted dying, the EOL trajectory is shortened to relieve suffering.

with no apparent recognition of the instances of assisted dying performed for other reasons than relief of (current) suffering, or when the person is (not yet) on an end of life (EOL) trajectory. This is not indicative of much progress.

Similarly, the 2008-2009 exchange between McLachlan and Coggon about the validity of the distinction between active and passive euthanasia points towards incompatible, but strongly held, views about the proper framing of the relevant question as a major hindrance to philosophical progress. ${ }^{14-16}$

\section{DO THE ARGUMENTS MATCH THE CONCERNS?}

Philosophers are primarily interested in arguments, but it is not obvious how or if the arguments we produce relate to the concerns that are put forward in the public debate or that people who do not participate in the public debate hold. Häyry ${ }^{17}$ discusses this issue in an article published in the JME in 2005 and his conclusion is worth quoting at length:

Arguments can voice, clarify, create, and tackle concerns. If the concerns in question are philosophical, they can be conceptually addressed and, in so far as theoretical consensus can be reached, settled.

\section{$[\ldots]$}

In the case of concerns which involve moral, cultural, or emotional norms, values, or expectations, arguments can, and 
probably should, be rehearsed to make explicit the underlying ethical assumptions. The eventual choice between these assumptions falls, however, outside the scope of arguments, understood as attempts to arrive, by the use of words, at universally acceptable solutions.

The concerns that remain can be addressed by reassurances and actions. The actions available to authorities include, in addition to promises and regulations, efforts to communicate with the public and to prompt consensus formation. Philosophical reflections and arguments can have a legitimate role in these activities. If the decisions reached are truly acceptable to all those involved, the initial concerns have effectively been accounted for. But if some, or many, people are still concerned, repeated or additional philosophical arguments are not the answer. [p. 600]

At least some of the concerns in relation to PAD do not seem to be adequately addressed by the arguments in the literature.

Conscientious objection to PAD is often assumed as 'the solution' to assuage the concerns of doctors and other healthcare professionals who do not want to participate in PAD or do not want PAD to be part of medical practice. But it is not obvious that conscientious objection adequately addresses the concerns, ${ }^{18}$ even in relation to those doctors who are in ignorance of the considerable philosophical literature arguing that conscientious objection should be abolished or curtailed in relation to the provision of elective abortion. ${ }^{19-21}$ The concerns doctors have may not only be personal or fully captured by 'I do not want to perform PAD'; they are often about a wider set of actions than direct performance, and often about changes in healthcare that will inevitably follow the introduction of PAD, and can perhaps be more accurately expressed as introducing PAD will inevitably make it part of the context of my professional life, and that worries me because it will change that life'. This wider or broader concern involves both a set of basic ethical assumptions and some more practical concerns that need reassurance and policy action. Here it is interesting to note in a UK context that, whereas Lord Joffe's 2005 assisted suicide bill tried to provide effective assurance, Lord Falconer's current bill is much less reassuring for those who hold these concerns, as can be seen by comparing the two relevant paragraphs. First, Lord Joffe's Bill:

\section{Conscientious objection}

1. No person shall be under any duty to participate in any diagnosis, treatment or other action authorised by this Act, apart from subsection (6), to which he has a conscientious objection.

2. No hospice, hospital, nursing home, clinic or other health care establishment shall be under any obligation to permit an assisted death on its premises.

3. No person shall be under any duty to raise the option of assisted dying with a patient, to refer a patient to any other source for obtaining information or advice pertaining to assistance to die, or to refer a patient to any other person for assistance to die under the provisions of this Act.

4. If an attending physician whose patient makes a request to be assisted to die in accordance with this Act has a conscientious objection as provided in subsection (1), the patient shall be free to consult another physician who does not have a conscientious objection and who, for the purposes of this Act, shall then be the patient's attending physician.

5. If a consulting physician to whom a patient has been referred in accordance with section (2)(i) has a conscientious objection as provided in subsection (1), the patient shall be free to consult another consulting physician who does not have a conscientious objection and who, for the purposes of this Act, shall then be the patient's consulting physician.

6. Where a patient has consulted a physician under subsection (4) or (5) the physician who has a conscientious objection shall immediately, on receipt of a request to do so, transfer the patient's medical records to the new physician. ${ }^{22}$

Then Lord Falconer's Bill:

\section{Conscientious objection}

A person shall not be under any duty (whether by contract or arising from any statutory or other legal requirement) to participate in anything authorised by this Act to which that person has a conscientious objection. ${ }^{23}$

Another example of the failure of arguments to meet concerns in the PAD context is in relation to the voluntariness of euthanasia, where the philosophical tripartite distinction between voluntary, non-voluntary and involuntary euthanasia may not align with concerns about the various social or economic pressures that may lead a person to ask for euthanasia voluntarily.

\section{ETHICS OR POLITICAL PHILOSOPHY?}

In the academic PAD debate there is a tendency to conflate or elide the differences between ethics, policy and law, despite the fact that all the participants know that there is a difference between ethics and law and that there is no direct relation between the propositions that an act is morally acceptable and that it should be legally permitted (or vice versa). However, the chasm between ethics and law is often 'bridged' in one or more of three interrelated ways by scholars arguing for a more liberal legal approach: (1) by reference to liberal values and/or Mill's harm principle; (2) by a philosophical-legal 'application' of one of the human rights enunciated in a major human rights document (eg, the European Convention of Human Rights); or (3) by claiming that access to PAD is necessary for protecting important interests. On the other side of the debate it is often seen as sufficient to show that there is some ethical problem with PAD or its implementation in order to show that PAD should not be legalised without making out a full case for prohibition.

Both approaches are clearly deficient in their understanding of the interplay between law and ethics. One does not have to be a legal positivist and deny any principled connection between law and ethics to realise that, in an area as complex and context-dependent as the possible introduction of PAD into a particular healthcare system, there are no 'hole in one' arguments that are decisive either way when it comes to policy formation. But the elision of ethics and policy is much more understandable if the papers are seen to have a dual purpose, both academic analysis and social activism.

\section{CONCLUSION}

Reading papers on the PAD debate in the first 40 years of the $J M E$ shows that there is some progress in medical ethics, but it also shows that many contributions sit on the borderline between applied ethics and social activism - that is, that they are written both as academic contributions and as opinion pieces advocating social change (or status quo) in relation to PAD. The authors of such papers have the answers to the question ostensibly raised in their papers before even starting their research, and their papers' primary purpose is to support their already predetermined answer. The frequency of such 'mixed' papers also illustrates one of the difficulties in doing good 
philosophical medical ethics. A nuanced analysis taking account of both the concerns of non-philosophers and the arguments of one's philosophical opponents is unlikely to be an effective intervention in the policy debate. A more rhetorical piece, on the other hand, is unlikely to be as effective an intervention in the philosophical debate. Both pieces of work can be good medical ethics, but they are good in very different ways. And it would - at least sometimes-be useful to the reader to know which of these sub-genres a particular paper belongs to: is it a contribution to a philosophical debate or is it advocacy for a particular policy option?

Competing interests None.

Provenance and peer review Commissioned; internally peer reviewed.

\section{REFERENCES}

Nicholson R. Should the patient be allowed to die? J Med Ethics 1975;1:5-9.

2 Winget C, Kapp FT, Yeaworth RC. Attitudes towards euthanasia. J Med Ethics 1977;3:18-25.

3 van Delden JJM. Terminal sedation: source of a restless ethical debate. J Med Ethics 2007;33:187-8.

4 Emanuel EJ. Euthanasia and physician-assisted suicide: a review of the empirical data from the United States. Arch Intern Med 2002;162:142-52.

5 Duncan OD, Parmelee LF. Trends in public approval of euthanasia and suicide in the US, 1947-2003. J Med Ethics 2006;32:266-72.

6 Gillon R. Euthanasia in The Netherlands-down the slippery slope? J Med Ethics 1999;25:3-4.
7 Battin MP, van der Heide A, Ganzini L, et al. Legal physician-assisted dying in Oregon and the Netherlands: evidence concerning the impact on patients in "vulnerable" groups. J Med Ethics 2007;33:591-7.

8 Jochemsen $\mathrm{H}$, Keown J. Voluntary euthanasia under control? Further empirical evidence from The Netherlands. J Med Ethics 1999;25:16-21.

9 van Delden JJ. Slippery slopes in flat countries-a response. J Med Ethics 1999;25:22-4.

10 Keown J, Jochemsen H. Voluntary euthanasia in The Netherlands. J Med Ethics $1999 ; 25: 351-2$

11 Coggon J. Law, ethics and medicine: arguing about physician-assisted suicide: a response to Steinbock. J Med Ethics 2006;32:339-41.

12 Rorty R. Truth and progress_-philosophical papers. New York: Cambridge University Press, 1998.

13 Rady MY, Verheijde JL. Distress from voluntary refusal of food and fluids to hasten death: what is the role of continuous deep sedation? J Med Ethics 2012;38:510-12.

14 McLachlan HV. The ethics of killing and letting die: active and passive euthanasia. J Med Ethics 2008;34:636-8.

15 Coggon J. On acts, omissions and responsibility. J Med Ethics 2008;34:576-9.

16 McLachlan HV. To kill is not the same as to let die: a reply to Coggon. J Med Ethics 2009;35:456-8.

17 Häyry M. Can arguments address concerns? J Med Ethics 2005;31:598-600.

18 Holm S. Euthanasia: agreeing to disagree? Med Health Care Philos 2010;13:399-402.

19 Meyers C, Woods RD. An obligation to provide abortion services: what happens when physicians refuse? J Med Ethics 1996:22:115-20.

20 Savulescu J. Conscientious objection in medicine. BMJ 2006;332:294-7.

21 Minerva F. Conscientious objection in Italy. J Med Ethics. Published Online First: 26 May 2014. doi:10.1136/medethics-2013-101656

22 Assisted Dying for the Terminally III Bill [HL] 2005-6.

23 Assisted Dying Bill [HL] 2013-14. 